\title{
Utilization of the nutrients in the soluble and insoluble fractions of fungal mycelium by larvae of the stag beetle, Dorcus rectus (Coleoptera: Lucanidae)
}

\author{
MASAHIKo TANAHASHI ${ }^{1}$ and KôHeI KUBOTA ${ }^{2}$ \\ ${ }^{1}$ National Institute of Advanced Industrial Science and Technology (AIST), Central 6, Tsukuba, Ibaraki 305-8566, Japan; \\ e-mail: m-tanahashi@aist.go.jp \\ ${ }^{2}$ Laboratory of Forest Zoology, Graduate School of Agricultural and Life Sciences, The University of Tokyo, Yayoi, Bunkyo-ku, \\ Tokyo 113-8657, Japan; e-mail: kohei@fr.a.u-tokyo.ac.jp
}

Key words. Coleoptera, Lucanidae, Dorcus rectus, saproxylophagous insects, fungal cell wall, chitin, digestion, symbiotic microorganisms, Bjerkandera adusta mycelium

\begin{abstract}
Larvae of the stag beetle, Dorcus rectus, feed on decaying wood, which they digest with the aid of symbiotic yeasts; however, they can be successfully reared on artificial diets containing only fungal tissue. In this study we tested whether $D$. rectus larvae can utilize fungal cell walls, which are an insoluble component of mycelium. Lyophilized Bjerkandera adusta mycelium cultured in potato-dextrose liquid medium consisted of a $47.6 \%$ hot-water insoluble fraction by mass, which contains $53.7 \%$ of the total nitrogen in the mycelium. D. rectus larvae that hatched from surface-sterilized eggs were reared for 14 days on agar-based diets containing either the soluble fraction, insoluble fraction or both, extracted from $100 \mathrm{mg}$ of mycelium. The larvae increased in mass most on the mixed diet, and there was no difference in their growth on the mixed and positive control diets. Both the soluble and insoluble fractions improved larval growth compared to the negative control diet; however, the growth rates were much lower than those expected from the nitrogen dose-growth response curve obtained in a previous study. Addition of $\beta$-chitin to the soluble fraction did not positively affect larval growth. Therefore, we conclude that (1) D. rectus larvae need both the soluble and insoluble fractions of mycelium and (2) the larvae digest the insoluble fraction using their own enzymes.
\end{abstract}

\section{INTRODUCTION}

Solubility is one of the key factors determining food quality. Since soluble nutrients are more easily digested and quickly absorbed than insoluble ones, the amount and balance of soluble nutrients dramatically affect the growth, survival and fecundity of animals such as cows (Janicki et al., 1985), rats (Bronner, 1993), birds (Jefferies \& Edwards, 2008) and insects (Awmack \& Leather, 2002). Phytophagous insects feed mainly on the soluble components of plant tissues and rarely digest lignocelluloses, which are the main constituents of plant cell walls (Risebrow \& Dixon, 1987; Haack \& Slansky, 1987). Of plant tissues, wood is the most abundant in terms of biomass of terrestrial plants (Poorter et al., 2012). Since wood is composed of almost 90\% lignocelluloses (Parkin, 1940) and contains only 2-10\% water-soluble substances (Mahood \& Cable, 1922; Browning, 1963; Kilic \& Niemz, 2012), it is far more difficult for insects to utilize wood directly as food. Many wood-inhabiting insects have relationships with microorganisms, which help them digest wood. The best studied cases are termites and ambrosia beetles, which harbour symbiotic microorganisms in their guts or feeding tunnels that digest woody substrates (Cleveland, 1924; ; Batra, 1963; Slaytor, 1992; Breznak \& Brune, 1994; Geib et al., 2009). Most other wood-feeding insects are thought to be saproxylophagous, which means they feed on decaying wood that is infested with wood-rotting fungi. Saproxylophagous insects are likely to utilize both the fungal tissues and the woody substrates that are partially decomposed and solubilized by the wood-rotting fungi.

The "lesser" stag beetle, Dorcus rectus (Motschulsky) (Coleoptera: Lucanidae), is the dominant saproxylic insect in lowland temperate forests in Japan (Kubota \& Kubota, 2004). D. rectus females deposit eggs on decaying trunks and branches of hardwood trees that are usually infested with white-rot fungi (Araya, 1993; Kubota \& Kubota, 2004). Hatchling larvae burrow into decaying wood and consume the surrounding wood together with fungal tissue. After the adults emerge they feed on fermented sap that exudes from tree trunks and rotten fruit. Our previous study showed that D. rectus larvae can be reared on an artificial diet that only contains fungal mycelium (Tanahashi et al., 2009), therefore, $D$. rectus is thought to be fungivorous even though they feed on woody material. Moreover, adult $D$. rectus females harbour xylose-fermenting yeast in their mycangium (Tanahashi et al., 2010) and inoculate this yeast along with their eggs into decaying wood (M. Tanahashi, pers. observ.). The yeast may help the larvae to digest the decaying wood and is possibly consumed by larvae as food.

There are large amounts of insoluble polymers in the cell walls of fungi. However, unlike plants, chitin and/or $\beta$-1,3-glucan are the major components of cell walls of most species of fungi and yeast (Bowman \& Free, 2006; Kurtzman et al., 2011). Since fungal cell walls accumulate in decaying wood over time and are usually more digestible and nutritious than lignocelluloses, they are 
likely to be an important source of nutrients for saproxylophagous insects. However, few studies have focused on the utilization of fungal cell walls by saproxylophagous insects. We have already developed an agar-based artificial diet for microbe-free rearing of stag beetle larvae (Tanahashi et al., 2009). In this study, we show that (1) the agar-based artificial diet can be used to determine the nutrient requirements of stag beetle larvae, (2) they require both soluble and insoluble fractions of fungal mycelium and (3) they can digest the insoluble fraction without the aid of gut microbes.

\section{MATERIAL AND METHODS}

\section{Insects}

D. rectus females were collected in Hachioji City, Tokyo, Japan in 2005 and 2006. They were supplied with wood blocks for ovipositing on and the eggs were collected from the wood blocks every day (Tanahashi et al., 2009). The eggs were surface sterilized by treating them for $20 \mathrm{~s}$ with deionised water and then $99.5 \%$ ethanol, $70 \%$ ethanol twice and sterile deionized water in that order, and then incubated on moistened filter paper in Petri dishes at $25^{\circ} \mathrm{C}$ in the dark. Newly hatched larvae were weighed within one day of hatching and transferred to the artificial diets mentioned below.

\section{Artificial diets}

The white-rot fungus Bjerkandera adusta was cultured in potato dextrose liquid medium at $25^{\circ} \mathrm{C}$ for 10 days and the mycelium was collected by filtration as described by Tanahashi et al. (2009). The mycelium was freeze-dried and ground using a mortar and pestle to a fineness that passed through $0.5 \mathrm{~mm}$ mesh. For the hot water extraction, $1.2 \mathrm{~g}$ of lyophilized mycelium powder and $120 \mathrm{ml}$ of distilled water were added to a $500-\mathrm{ml}$ pear shaped flask attached to a reflux condenser and the flask placed in boiling water for $3 \mathrm{~h}$. The suspension was filtered through a glass-fiber filter, the weight of which was known. Residue on the filter was rinsed with $30 \mathrm{ml}$ of boiling distilled water and the water was then combined with the first filtrate. After that, the residue on the filter was rinsed with an additional $120 \mathrm{ml}$ of boiling distilled water and freeze-dried for 1 day. Net dry mass of the residue was determined by weighing it to the nearest $0.01 \mathrm{mg}$ on an electronic balance. The residue, which was included in the HWR diet as described below, was carefully scraped off the filter so as not to include glass fibers and then ground using a mortar and pestle to a fineness that would pass through a $0.5 \mathrm{~mm}$ mesh. Residual rate was calculated by dividing the net residual mass by initial mass. This procedure was repeated three times and the mean residual rate $R$ calculated.

For the diet containing the hot-water extract (HWE diet), preservatives were added to the extract, which was then diluted
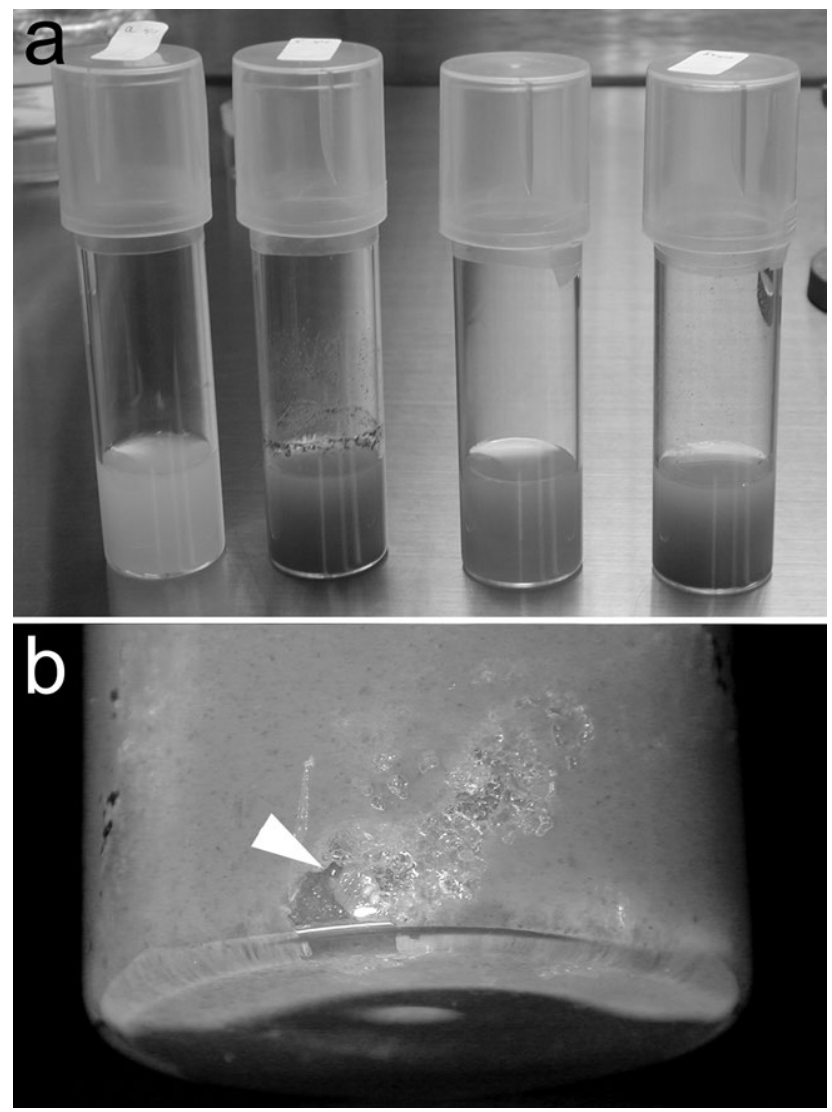

Fig. 1. Tubes containing the artificial diets used in this study. (a) Diet containing no mycelium (negative control), nonextracted freeze-dried Bjerkandera adusta mycelium (positive control), hot-water extract of the mycelium (HWE) and residue after hot-water extraction of the mycelium (HWR), in that order from left to right. (b) Dorcus rectus larva feeding on the positive control diet. The arrow indicates the head of the larva.

with distilled water (Table 1). Fifteen $\mathrm{ml}$ of the solution containing the extract and the preservative (equivalent to $100 \mathrm{mg}$ of mycelium) were added to $450 \mathrm{mg}$ of agar powder in a $50-\mathrm{ml}$ glass test tube $(27.3 \mathrm{~mm}$ inner diameter) with a flat bottom. These test tubes were each capped with a polypropylene cap and autoclaved at $121^{\circ} \mathrm{C}$ for $15 \mathrm{~min}$. When they had cooled to $50^{\circ} \mathrm{C}$, the test tubes were removed from the autoclave, stirred several times and allowed to cool down on a clean bench. For the diet containing the residue after hot-water extraction of the mycelium (HWR diet), $100 \times R \mathrm{mg}$ of the residue, $450 \mathrm{mg}$ agar and $15 \mathrm{ml}$ preservative solution were added to each test tube and autoclaved in the same way. For the mixed diet, $15 \mathrm{ml}$ of the solution containing the extract and preservative, $100 \times R \mathrm{mg}$ of

TABLE 1. Composition of the artificial diets for Dorcus rectus larvae using lyophilized Bjerkandera adusta mycelium.

\begin{tabular}{lcc}
\hline & Final concentration & For a single diet \\
\hline B.adusta mycelium (non-extracted), & $6.6 \mathrm{mg} / \mathrm{l} \mathrm{mycelium}$ & $100 \mathrm{mg}$ mycelium \\
hot-water extract or residue & (or equivalent) & $15.0 \mathrm{mg}$ \\
Ascorbic acid & $1.0 \mathrm{mg} / \mathrm{ml}$ & $12.5 \mathrm{mg}$ \\
Sorbic acid & $0.83 \mathrm{mg} / \mathrm{ml}$ & $16.5 \mathrm{mg}$ \\
Sodium hydrocarbonate & $1.1 \mathrm{mg} / \mathrm{ml}$ & $450 \mathrm{mg}$ \\
Agar & $30 \mathrm{mg} / \mathrm{ml}$ & (up to $15 \mathrm{ml}$ ) \\
Distilled water & & \\
\hline
\end{tabular}


the residue and $450 \mathrm{mg}$ agar were mixed and autoclaved. For the positive control diet (agar and preservative with $100 \mathrm{mg}$ of mycelium that had not been extracted; $\mathrm{n}=16$ ) and the negative control diet (agar and preservative without mycelium; $\mathrm{n}=15$ ), we cite the data published in Tanahashi et al. (2009) because both experiments were carried out in parallel. Tubes containing these artificial diets are shown in Fig. 1.

\section{Carbon and nitrogen content}

A part (ca. $30 \mathrm{mg}$ ) of the freeze-dried mycelium and the residue of hot-water extraction were subjected to carbon and nitrogen analysis using an elementary analyzer (CN Corder MT700, Yanaco, Japan). Carbon and nitrogen content of the hot water extract were estimated by subtracting each value for the residue from those for non-extracted mycelium. The carbon and nitrogen contents of each fraction are presented in two forms; (1) percentage values for the mass of each fraction and (2) percentage values for the initial mass of the non-extracted mycelium.

\section{Rearing procedure}

Immediately after weighing the hatchling larvae of $D$. rectus were placed individually on artificial diets in test tubes and reared at $25^{\circ} \mathrm{C}$ in the dark. After 14 days, the larvae were recovered from the test tubes and their body mass was determined again. Numbers of the larvae reared on the HWE, HWR and mixed diets were 15,12 and 10 , respectively.

In addition, three larvae were reared on HWE diets containing $30 \mathrm{mg}$ of $\beta$-crystalline chitin from squid cartilage $\left(\mathrm{HWE}^{+}\right)$in order to determine whether $D$. rectus larvae need insoluble polysaccharides as a feeding stimulant.

\section{Detection of microbes}

After the rearing period, each larva and a piece of the remaining diet were homogenised separately in sterile $1.5 \mathrm{ml}$ tubes and each homogenate was spread onto potato dextrose agar (PDA: Difco) and plate count agar (PCA: Eiken Chemical) plates. The plates were incubated at $25^{\circ} \mathrm{C}$ for 5 days.

\section{Data analyses}

Assuming an exponential growth during the initial 14 days of rearing (Tanahashi et al., 2009), the growth rate was calculated as $\log _{\mathrm{e}}$ (final body mass / initial body mass) / 14. The mean growth rate on each diet was compared using one-way ANOVA followed by Bonferroni's multiple comparisons of paired means at a significance level of 0.05 .

\section{RESULTS}

Dry mass of the lyophilized B. adusta mycelium was nearly halved following the hot water extraction (mean residual rate $R=0.476$ ). The carbon content of the extract was higher than that of the residue, whereas the nitrogen content was higher in the residue (Table 2). As a result, the $\mathrm{C} / \mathrm{N}$ ratio of the residue was much lower than of the

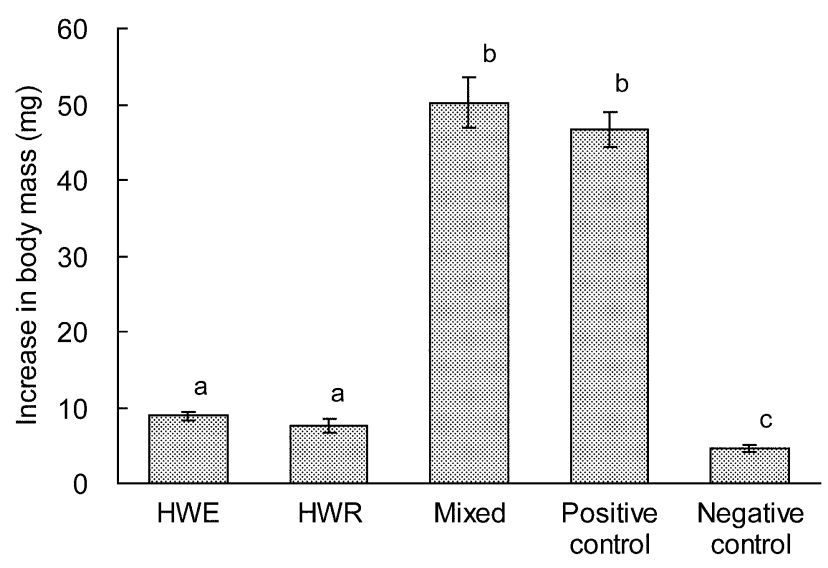

Fig. 2. Growth response of newly hatched Dorcus rectus larvae reared on each of the artificial diets. Values are the mean increase in mass of the larvae reared for 14 days on the hotwater extract of Bjerkandera adusta mycelium (HWE), hotwater residue (HWR), both extract and residue (mixed), positive control and negative control diets. Bars show \pm SE. Different letters above each column indicate a significant difference at the $5 \%$ level using one-way ANOVA followed by Bonferroni's multiple comparisons of paired means.

extract. The initial masses of the larvae were $6.8 \pm 0.2$ $\mathrm{mg}, 7.0 \pm 1.3 \mathrm{mg}$ and $6.7 \pm 1.4 \mathrm{mg}$ (mean \pm s.d.) and the numbers of the larvae that survived/supplied were $15 / 15$, $11 / 12$ and $8 / 10$ for the HWE, HWR and mixed diets, respectively. Larval growth recorded on the mixed diet $(50.2 \pm 3.4 \mathrm{mg})$ was greater than that recorded on the positive control diet $(46.7 \pm 7.9 \mathrm{mg})$ but they are not significantly different. The growth of the larvae that were reared on the HWE and HWR diets was significantly greater $(8.9 \pm 2.4 \mathrm{mg}$ and $7.6 \pm 2.7 \mathrm{mg}$, respectively) than that recorded on the negative control diet $(4.6 \pm 1.6 \mathrm{mg})$ (Fig. 2). The growth was not as good on the HWR as on the HWE diet, but not significantly different. However, the growth recorded in the HWE and HWR treatments were much lower than those estimated from the dosegrowth response curves for total mycelium mass (Fig. 3a) or nitrogen concentration (Fig. 3b). Addition of $\beta$-chitin to HWE diets did not positively affect larval growth (8.9 $\mathrm{mg}$ for $\mathrm{HWE}^{+}$diet, number of survived larvae = 1), although the feeding behaviour of the larvae changed: the larva made a wider tunnel in this diet and tended to stay longer at each site. Larvae in the early stages of their development seemed to have difficulty tunneling into the agar and it is likely that this was the primary cause of death of larvae in all the treatments.

TABLE 2. Carbon and nitrogen contents (mean \pm s.d.) of the hot-water extract and residue of lyophilized Bjerkandera adusta mycelium.

\begin{tabular}{|c|c|c|c|c|c|}
\hline Materials & $\mathrm{n}$ & Total mass $(\%)$ & Carbon (\%) & Nitrogen $(\%)$ & $\mathrm{C} / \mathrm{N}$ \\
\hline B. adusta mycelium (total) & 5 & 100.00 & $43.79 \pm 0.38$ & $4.23 \pm 0.18$ & $10.37 \pm 0.41$ \\
\hline $\begin{array}{l}\text { Hot-water extract } \\
\text { (soluble fraction) }\end{array}$ & 3 & $52.37 \pm 1.07$ & $\begin{array}{c}51.15 \pm 0.30 \\
(26.79 \pm 0.16)^{*}\end{array}$ & $\begin{array}{c}3.74 \pm 0.04 \\
(1.96 \pm 0.02)^{*}\end{array}$ & $13.69 \pm 0.05$ \\
\hline $\begin{array}{l}\text { Hot-water residue } \\
\text { (insoluble fraction) }\end{array}$ & 3 & $47.63 \pm 1.07$ & $\begin{array}{c}35.70 \pm 0.33 \\
(17.00 \pm 0.16)^{*}\end{array}$ & $\begin{array}{c}4.77 \pm 0.04 \\
(2.27 \pm 0.02)^{*}\end{array}$ & $7.48 \pm 0.01$ \\
\hline
\end{tabular}

\footnotetext{
* percentage values based on total mass of the non-extracted mycelium.
} 

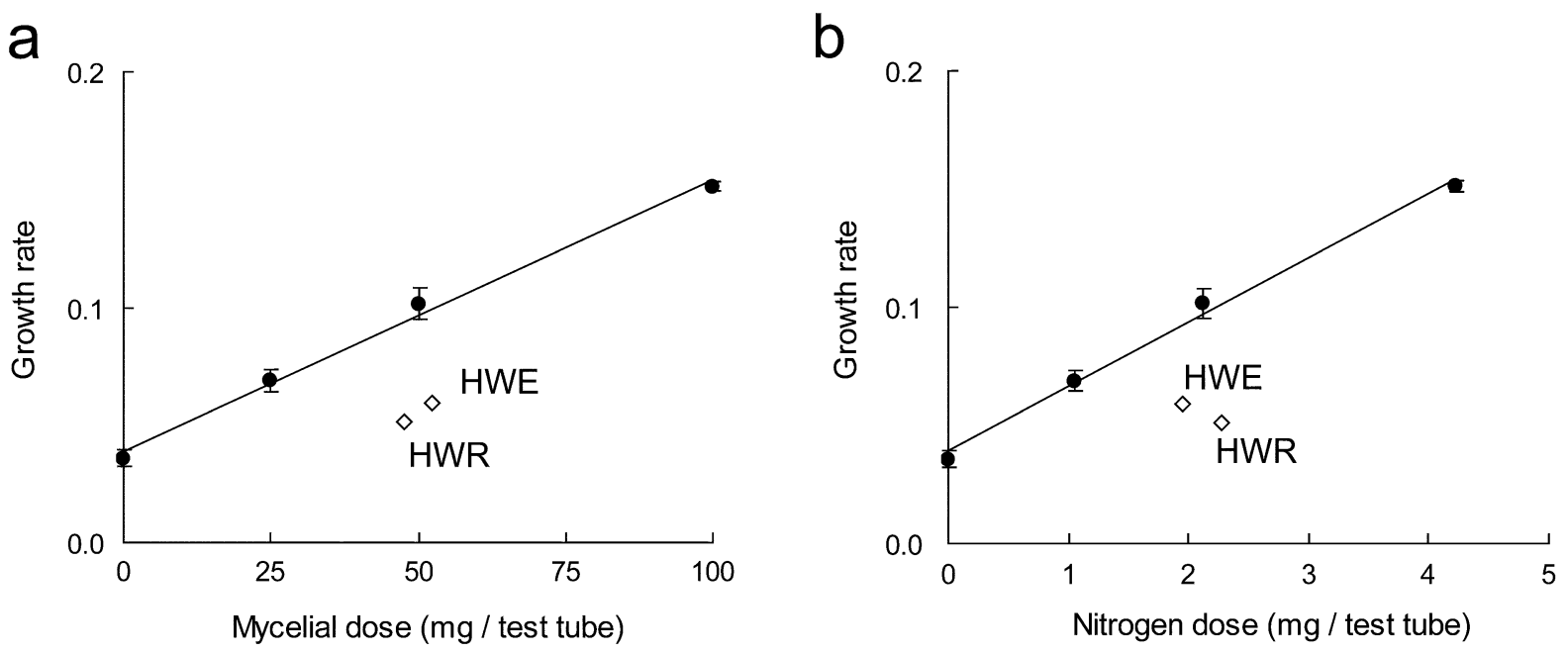

Fig. 3. Growth rate of newly hatched Dorcus rectus larvae reared on diets containing (a) different doses of mycelium and (b) nitrogen (after Tanahashi et al., 2009). Bars show \pm SE. Open diamonds indicate the mean growth rate when reared on diets containing the hot-water extract (HWE) and hot-water residue (HWR) of Bjerkandera adusta mycelium. There is only one point for each diet as the average mass was used to compare the growth on the different diets in this study.

No fungal or bacterial colonies developed on the PDA or PCA plates on which the homogenates of the larvae or remains of the diets were spread.

\section{DISCUSSION}

Newly hatched larvae of $D$. rectus significantly increased in mass when fed on the agar-based artificial diet that contained lyophilized mycelium of B. adusta. The larvae hardly increased in mass when fed on the artificial diets that contained only the hot-water extract or the residue of the lyophilized mycelium, both of which represent almost half the mass of the mycelium. Larval growth was fully restored when the two fractions were mixed, suggesting that the extraction process did not affect the quality or quantity of nutrients. No fungi, yeasts or culturable bacteria were detected in the larvae or in the diets on which larvae were reared. As a result, we conclude that the larvae of $D$. rectus need both the soluble and insoluble components of mycelium for normal growth and their own enzymes can digest the insoluble components.

The hot-water soluble fraction, which corresponds to the HWE diet, contained $52.4 \%$ of the mass of the lyophilized mycelium of B. adusta and $46.3 \%$ of the nitrogen in the mycelium. The HWE diet would also have contained soluble sugars, amino acids and minerals, which are essential or non-essential nutrients. However, the mean growth of the larvae of $D$. rectus on HWE diets was much lower than that expected from the nitrogen dose-growth response curve published by Tanahashi et al. (2009). Therefore we hypothesized that the HWR diet also includes some essential nutrients and/or feeding stimulants.

The hot-water insoluble fraction, which corresponds to the HWR diet, contained $47.6 \%$ of the mass of the lyophilized B. adusta mycelium and had a $\mathrm{C} / \mathrm{N}$ ratio that was much lower than that of the soluble fraction; therefore, the insoluble fraction is likely to be a potential nitrogen source. Fungal cell walls, which account for a large part of the water insoluble fraction, consist mainly of polysaccharides such as chitin (co-polymer of $N$-acetyl-glucosamine and $N$-glucosamine) and $\beta$-1,3-glucan (Selitrennikoff, 2001). Chitin is known to be an important nitrogen source for mycorrhizal fungi (Leake \& Read, 1990) and bacteria (Streichsbier, 1983; Killiny et al., 2010). However, it is still uncertain whether insects can utilize chitin as a nutrient; for example, predatory insects are unlikely to digest the chitinous exoskeleton of their insect prey (Wilder et al., 2010). Glucosamine content of lyophilized $B$. adusta mycelium cultured on birch wood determined using acid hydrolysis analysis (Jones \& Worrall, 1995) was $1.71 \%$ and the nitrogen content of purified chitin of the edible mushroom Pleurotus ostreatus is 5.9\% (Tshinyangu \& Hennebert, 1996). Applying those conversion factors to our results, chitinous nitrogen represents only $2.4 \%$ of the total nitrogen in B. adusta mycelium and $5.1 \%$ of that in the water insoluble fraction. This indicates that chitin was not the major source of nitrogen for the larvae and other nitrogen-rich substrates such as superficial mannoproteins and other membrane-associated proteins, which are combined with the chitin-glucan matrix layer (Selitrennikoff, 2001), might account for the high nitrogen content of the insoluble fraction.

Insoluble polysaccharides often aid swallowing in phytophagous insects. Silkworm needs cellulose in order to swallow mulberry leaves (Hamamura et al., 1962). Cellulose is commonly added to the artificial diets of lepidopteran insects and some wood-feeding insects as substitute for wood (Dubois et al., 2002; Gindin et al., 2009). In our experiment, agar might partially compensate for the lack of cellulose as D. rectus larvae fed normally on the artificial diets. However, larvae changed their feeding behaviour when $\beta$-chitin was added to the HWE diet, suggesting that they use insoluble polysaccharides as a feeding signal. $D$. rectus larvae may not be able to digest 
chitin since the addition of $\beta$-chitin to the HWE diet did not positively affect larval growth. However, chitin is possibly digested by gut microorganisms in nature and the nutritional importance of fungal chitin should be addressed in future studies.

ACKNOWLEDGEMENTS. We are grateful to K. Togashi for his helpful advice. We also thank N. Matsushita and T. Kagaya for technical support and suggestions. This study was supported by a research fellowship and Grants-in-Aid (nos. 19658059, 20148015) from the Japan Society for the Promotion of Science (JSPS).

\section{REFERENCES}

ARAYA K. 1993: Relationships between decay types of dead wood and occurrence of lucanid beetles (Coleoptera: Lucanidae). - Appl. Entomol. Zool. 28: 27-33.

Awmack C.S. \& Leather S.R. 2002: Host plant quality and fecundity in herbivorous insects. - Annu. Rev. Entomol. 47: 817-844.

BATRA L.R. 1963: Ecology of ambrosia fungi and their dissemination by beetles. - Trans. Kans. Acad. Sci. 66: 213-236.

Bowman S.M. \& Free S.J. 2006: The structure and synthesis of the fungal cell wall. - Bioessays 28: 799-808.

BreznaK J.A. \& Brune A. 1994: Role of microorganisms in the digestion of lignocellulose by termites. - Annu. Rev. Entomol. 39: 453-487.

BRONNER F. 1993: Nutrient bioavailability, with special reference to calcium. - J. Nutr. 123: 797-802.

Browning B.L. 1963: The Chemistry of Wood. Interscience Publishers, New York, $689 \mathrm{pp}$.

Cleveland L.R. 1924: The physiological and symbiotic relationships between the intestinal protozoa of termites and their host, with special reference to Reticulitermes flavipes (Kollar). — Biol. Bull. 46: 203-223.

Dubois T., Hajek A.E., Smith S. 2002: Methods for rearing the Asian longhorned beetle (Coleoptera: Cerambycidae) on artificial diet. - Ann. Entomol. Soc. Am. 95: 223-230.

Geib S.M., Filley T.R., Hatcher P.G., Hoover K., Carlson J.E., Jimenez-Gasco M., Nakagawa-Izumi A., Sleighter R.L. \& TIEN M. 2009: Lignin degradation in wood-feeding insects. - Proc. Natl. Acad. Sci. USA 105: 12932-12937.

Gindin G., Kuznetsova T., Protasov A., Yehuda S.B. \& Mendel Z. 2009: Artificial diet for two flat-headed borers, Capnodis spp. (Coleoptera: Buprestidae). - Eur. J. Entomol. 106: $573-581$.

HaAck R.A. \& SLAnsky F. 1987: Nutritional ecology of woodfeeding Coleoptera, Lepidoptera, and Hymenoptera. In Slansky F. \& Rodriquez J.G. (eds): Nutritional Ecology of Insects, Mites, Spiders, and Related Invertebrates. John Wiley, New York, pp. 449-456.

Hamamura Y., Hayashiya K., Naito K., Matsuura K. \& NishidA J. 1962: Food selection by silkworm larvae. Nature 194: 754

JANICKI F.J., Holter J.B. \& Hayes H.H. 1985: Varying protein content and nitrogen solubility for pluriparous, lactating Hol- stein cows: digestive performance during early lactation. $-J$. Dairy Sci. 68: 1995-2008.

JEFFERIES R.L. \& EDWARDS K.A. 2008: Soluble carbohydrate content of shoot of Arctic wetland plants that are consumed by lesser snow geese. - Botany 86: 995-1001.

Jones H.L. \& WorRaLl J.J. 1995: Fungal biomass in decayed wood. - Mycologia 87: 459-466.

Kilic A. \& NiemZ P. 2012: Extractives in some tropical woods. — Eur. J. Wood Prod. 70: 79-83.

Killiny N., Prado S.S. \& Almeida R.P.P. 2010: Chitin utilization by the insect-transmitted bacterium Xylella fastidiosa. Appl. Environ. Microbiol. 76: 6134-6140.

Kuвota K. \& Kuвota N. 2004: Beetles of genus Dorcus (Coleoptera: Lucanidae) boring into dead wood of willow trees Salix spp. - J. Tree Health 8: 17-22.

Kurtzman C.P., Fell J.W., Boekhout T. \& Robert V. 2011: Methods for isolation, phenotypic characterization and maintenance of yeasts. In Kurtzman C.P., Fell J.W. \& Boekhout T. (eds): The Yeasts, a Taxonomic Study. 5th ed. Elsevier, London, pp. 87-110.

LeAKe J.R. \& READ D.J. 1990: Chitin as a nitrogen source for mycorrhizal fungi. - Mycol. Res. 94: 993-995.

Mahood S.A. \& CABLE D.E. 1922: The chemistry of wood IV the analysis of the wood of Eucalyptus globulus and Pinus monticola. - J. Ind. Eng. Chem. 14: 933-934.

PARKIN E.A. 1940: The digestive enzymes of some wood-boring beetle larvae. - J. Exp. Biol. 17: 364-377.

Poorter H., Niklas K.J., Reich P.B., Oleksyn J., Poot P. \& Mommer L. 2012: Biomass allocation to leaves, stems and roots: meta-analyses of interspecific variation and environmental control. - New Phytol. 193: 30-50.

Risebrow A. \& Dixon A.F.G 1987: Nutritional ecology of phloem-feeding insects. In Slansky F. \& Rodriquez J.G. (eds): Nutritional Ecology of Insects, Mites, Spiders, and Related Invertebrates. John Wiley, New York, pp. 421-448.

SeltrenNikofF C.P. 2001: Antifungal proteins. - Appl. Environ. Microbiol. 67: 2883-2894.

Slaytor M. 1992: Cellulose digestion in termites and cockroaches: what role do symbionts play? - Comp. Biochem. Physiol. (B) 103: 775-784.

StreichSBIER F. 1983: Utilization of chitin as sole carbon and nitrogen source by Chromobacterium violaceum. - FEMS Microbiol. Lett. 19: 129-132.

Tanahashi M., Matsushita N. \& Togashi K. 2009: Are stag beetles fungivorous? - J. Insect Physiol. 55: 983-988.

Tanahashi M., Kubota K., Matsushita N. \& Togashi K. 2010 Discovery of mycangia and the associated xylose-fermenting yeasts in stag beetles (Coleoptera: Lucanidae). - Naturwissenschaften 97: 311-317.

Tshinyangu K.K. \& Hennebert G.L. 1996: Protein and chitin nitrogen contents and protein content in Pleurotus ostreatus var. columbinus. - Food Chem. 57: 223-227.

Wilder S.M., Mayntz D., Toft S., Rypstra A.L., Pilati A. \& VANNI M.J. 2010: Intraspecific variation in prey quality: a comparison of nutrient presence in prey and nutrient extraction by predators. - Oikos 119: 350-358.

Received April 3, 2013; revised and accepted May 9, 2013 